\title{
Adherence to the Mediterranean diet and risk of functional constipation in children in Turkey: case-control study
}

Ulas Akbulut, ${ }^{1}$ Ishak Isik, ${ }^{1}$ Atike Atalay' ${ }^{1}$ and Ismail Topal ${ }^{2}$

${ }^{1}$ Department of Pediatric Gastroenterology Hepatology and Nutrition, University of Health Sciences, Antalya Education and Research Hospital, Antalya, Turkey. ${ }^{2}$ Department of Pediatric Diseases, Erzincan University School of Medicine, Erzincan, Turkey (Correspondence to: Ulas Akbulut: ulasemre@ hotmail.com).

\begin{abstract}
Background: Functional constipation is often seen in children, affecting quality of life and imposing a considerable burden on health care services. The Mediterranean diet is associated with a lower risk of functional gastrointestinal disorders.

Aims: This study aimed to evaluate the relationship between functional constipation and adherence to the Mediterranean diet in Turkish children aged 6-18 years.

Methods: In this case-control study, 221 children with functional constipation (cases) were selected from a paediatric gastroenterology clinic between May 2018 and September 2019, and 230 children without constipation (controls) were randomly selected from those attending a well-child check-up. Cases and controls were matched on sex, age and socioeconomic characteristics. Compliance with the Mediterranean diet was assessed using the KIDMED index score. Multivariable logistic regression analysis was used to analyses the data.

Results: KIDMED index scores in cases and controls were $4.0(\mathrm{SD}=2.5)$ and $6.3(\mathrm{SD}=2.4)$, respectively $(P<0.001)$. Odds ratios for functional constipation were 0.23 (95\% confidence interval (CI): $0.13-0.38$ ) for KIDMED index score 4-7 and 0.05 (95\% CI: 0.03-0.11) for score $\geq 8$ compared with the lowest category (score $\leq 3 ; P<0.001$ ). A negative correlation was observed between age and adherence to the Mediterranean diet.

Conclusion: Good adherence to the Mediterranean diet was associated with a lower risk of functional constipation, and adherence to the Mediterranean diet decreased with age. Education on nutrition and health is warranted to help maintain and improve the health of young people in Turkey.

Keywords: constipation, child, adolescent, Mediterranean diet, Turkey

Citation: Akbulut U; Isik I; Atalay A; Topal I. Adherence to the Mediterranean diet and risk of functional constipation in children in Turkey: case-control study. East Mediterr Health J. 2021;27(6):587-594. https://doi.org/10.26719/2021.27.6.587

Received: 10/04/20; accepted: 07/10/20

Copyright (c) World Health Organization (WHO) 2021. Open Access. Some rights reserved. This work is available under the CC BY-NC-SA 3.0 IGO license (https://creativecommons.org/licenses/by-nc-sa/3.o/igo).
\end{abstract}

\section{Introduction}

Functional constipation is often seen in children and has an estimated global prevalence of 9.5\% (1). The condition affects the quality of life of children and parents and is a significant burden on health care services (2). Functional constipation is characterized by a slowing of bowel movements with no structural or biochemical disorder, painful defecation and sometimes faecal incontinence (3). Functional constipation in children is diagnosed clinically and using the Rome criteria (4). The pathophysiology of constipation in children is involves many factors. The most common cause is avoidance of defecation following difficult and painful defecation. Factors also leading to functional constipation include genetic disposition, low socioeconomic status, impaired mobility and insufficient daily fibre intake (5). Studies have reported a greater disposition to constipation in children with low vegetable, fruit and cereal consumption and low fibre intake $(6,7)$.

The Mediterranean diet is one of the most frequently described and evaluated dietary models in the scientific literature (8). This diet is very important for healthy life and has been shown to have preventative effects on some diseases such as cardiovascular diseases, metabolic diseases, and various cancers $(9,10)$. In addition to its high fibre and antioxidant levels and low saturated fatty acids and oligosaccharides, the Mediterranean diet may also be useful in improving functional gastrointestinal symptoms. A recent study reported a low prevalence of functional constipation in children with good adherence to the Mediterranean diet (11).

Antalya is in the Mediterranean region of Turkey in the north-east of Mediterranean. The dietary habits in the Antalya region include a high consumption of cereals, olive oil, fruits and vegetables, and water and milk products. Olives, olive oil and cereals are important in the Mediterranean dietary culture and are known to have been grown and used in the region since ancient times. The purpose of this study was to investigate the relationship between functional constipation and adherence to the Mediterranean diet in the Antalya region of Turkey. We hypothesized that constipation will be seen less frequently in children consuming a Mediterranian diet becasue of its high fibre content and antioxidative effect. 


\section{Methods}

\section{Study design and setting}

We conducted a case-control study at the Pediatric Gastroenterology Department of the Antalya Education and Research Hospital, Turkey. The hospital is a tertiary health centre in the Mediterranean region of Turkey, and serves an urban area where mostly middle-income families live. The study was conducted between May 2018 and September 2019.

\section{Cases and controls}

We recruited two groups of children aged 6-18 years. Cases (Group 1) were patients diagnosed with functional constipation $(n=221)$ by our paediatric gastroenterology unit. Controls (group 2) were 230 healthy children (matched on sex, age and socioeconomic characteristics) who had no previous history of chronic health problems and organic gastrointestinal disorders; control children were randomly selected from those attending our clinic for a well-child check-up.

Functional constipation was diagnosed by questioning both parents and the patient using the Rome IV criteria (4) - constipation for at least 1 month and including at least two of the following: two or fewer defecations a week; faecal incontinence more than once a week; retentive posturing; painful or hard bowel movements; large faecal mass in rectum; and large stool diameter. Exclusion criteria were: previous diagnosis of organic causes of defecation disorders; suspected gastrointestinal obstruction; abdominal or rectal surgery that might affect constipation; or any other conditions that cause the chronic constipation. Children in both the case and control groups were also excluded if they had severe neurological or mental disorders.

The control group underwent routine clinical examinations to check their health status, after excluding the presence of a functional chronic constipation during the clinical interview. Participants were further classified into two age subgroups: children attending elementary school (age 6-12 years, $n=288$ ) and high-school students (age 13-18 years, $n=163$ ).

We recorded data on some confounding variables, namely maternal and paternal education and socioeconomic status of family. Maternal and paternal educational level was reported by the parents and categorized into three groups: primary school and below, secondary school and university. Socioeconomic status of family was evaluated using the family affluence scale, which has been used in the Turkish setting before $(12,13)$. Socioeconomic status was categorized into three levels based on the score on the family affluence scale: level 1 low prosperity (score: $0-3$ ), level 2 moderate prosperity (score: $4-5$ ) and level 3 high prosperity (score: $6-7$ ).

\section{Anthropometric measurements}

For all cases and controls, anthropometric measurements were collected by the same trained operator. Height was measured to the nearest centimetre using a Harpenden stadiometer (Holtain Instruments Ltd, UK). Weight was measured in underwear to the nearest $0.1 \mathrm{~kg}$ using a calibrated balance scale. Body mass index (BMI) was calculated using the equation: weight $(\mathrm{kg}) /$ height squared $\left(\mathrm{m}^{2}\right)$. BMI values were categorized according to the World Health Organization criteria as follows: $<18.5$ $\mathrm{kg} / \mathrm{m}^{2}=$ underweight, $18.5-24.9 \mathrm{~kg} / \mathrm{m}^{2}=$ normal weight, $25-29.9 \mathrm{~kg} / \mathrm{m}^{2}=$ overweight and $\geq 30 \mathrm{~kg} / \mathrm{m}^{2}=$ obese (14).

\section{Adherence to the Mediterranean diet}

Adherence to the Mediterranean diet was assessed using the KIDMED index (15). This index includes 16 questions that summarize the characteristics of the Mediterranean diet. Twelve questions in the KIDMED index have a positive connotation with the Mediterranean diet (e.g. consumes olive oil at home) and four have a negative connotation (e.g. consumes sweets and candy several times a day). We used the previously validated Turkish language version of the questionnaire (16). A score of +1 was given for affirmative responses to positive questions (o for negative responses), and a score of -1 was given for affirmative responses to negative questions (o for negative responses). The total possible score ranges between 0 and 12. A KIDMED index score of $\geq 8$ indicates optimal adherence to the Mediterranean diet (good), scores of 4-7 indicate that adherence to the Mediterranean diet needs to be improved (moderate), and scores of $\leq 3$ indicate low adherence to the Mediterranean diet and poor nutritional quality (low).

\section{Statistical analysis}

We used SPSS 13.0 (SPSS Inc., Chicago, IL, USA) software for data analyses. In our descriptive analysis, categorical variables were expressed as number and percentage, and continuous variables were expressed as mean and standard deviation (SD). Normally distributed variables were compared between the cases and controls using the independent samples t-test. Non-normally distributed variables were compared using the Mann-Whitney U test. We used the chi-squared test to compare categorical variables.

The potential confounding variables were included in a final univariate and multivariable logistic regression analysis: age (years, continuous), sex (reference category: females), BMI status ( reference category: obese), maternal and paternal educational level (reference category: primary school and below), and socioeconomic status of family (reference category: level 1, low prosperity). In addition, with the KIDMED index as the dependent variable regression analysis was performed with agematching. Conditional logistic regression models were used to estimate odds ratios (ORs) and 95\% confidence intervals $(\mathrm{CI}) . P<0.05$ was considered statistically significant.

\section{Ethical concerns}

The study was approved by ethical committee of University of Health Sciences, Antalya Education and Research Hospital (registry url: 2019-17/2). The study was con- 


\begin{tabular}{|c|c|c|c|}
\hline Variable & Cases $(n=221)$ & Controls $(n=230)$ & P-value ${ }^{a}$ \\
\hline Age in years, mean (SD) & $9.0(3.8)$ & $9.1(3.2)$ & 0.247 \\
\hline Sex, female, no. (\%) & $122(52.2)$ & $118(51.3)$ & 0.487 \\
\hline BMI in $\mathrm{kg} / \mathrm{m}^{2}$, mean (SD) & $18.8(3.1)$ & 18.3(3.2) & 0.835 \\
\hline BMI category, no. (\%) & & & 0.285 \\
\hline Underweight & $11(5.0)$ & $12(5.2)$ & \\
\hline Normal weight & $135(61.1)$ & $158(68.7)$ & \\
\hline Overweight & $55(24.9)$ & $47(20.4)$ & \\
\hline Obese & $20(9.0)$ & $13(5.6)$ & \\
\hline Maternal educational level, no. (\%) & & & 0.301 \\
\hline Primary school and below & $69(31.2)$ & $55(23.9)$ & \\
\hline Secondary school & $117(52.9)$ & $123(53.5)$ & \\
\hline University & $35(15.8)$ & $52(22.6)$ & \\
\hline Paternal educational level, no. (\%) & & & 0.235 \\
\hline Primary school and below & $40(18.1)$ & $31(13.5)$ & \\
\hline Secondary school & $86(38.9)$ & $84(36.5)$ & \\
\hline University & $95(43.0)$ & $115(50.0)$ & \\
\hline Socioeconomic status of family, no. (\%) & & & 0.065 \\
\hline Level 1 (low status) & $41(18.6)$ & $34(14.8)$ & \\
\hline Level 2 (moderate status) & $141(63.8)$ & $135(58.7)$ & \\
\hline Level 3 (high status) & $39(17.6)$ & $61(26.5)$ & \\
\hline KIDMED index score, mean (SD) & $4.0(2.5)$ & $6.3(2.4)$ & $<0.001$ \\
\hline Adherence to Mediterranean diet, no. (\%) & & & $<0.001$ \\
\hline Low $(\leq 3)$ & $95(43.0)$ & $25(10.9)$ & \\
\hline Moderate (4-7) & $108(48.9)$ & $124(53.9)$ & \\
\hline $\operatorname{High}(\geq 8)$ & $18(8.1)$ & $81(35.2)$ & \\
\hline
\end{tabular}

$B M I=$ body mass index $S D=$ standard deviation;

${ }^{a} P<0.05$ statistically significant.

ducted in accordance with the Declaration of Helsinki. Informed consent was obtained from the parent or legal guardian and the children signed a consent form (or gave verbal consent if they could not sign).

\section{Results}

\section{Participant characteristics}

A total of 451 participants completed a study, 221 functional constipation cases and 230 controls. The demographic characteristics of the cases and controls are shown in Table 1. There were no statistically significant differences between cases and controls for age, sex, BMI, socioeconomic status of family, and maternal and paterf nal education.

\section{KIDMED score and constipation}

KIDMED index scores in cases and controls were 4.0 (SD 2.5) and 6.3 (SD 2.4), respectively (Table 1), a statically significant difference $(P<0.001)$. Adherence to the Mediterranean diet was high in only $8.1 \%$ of the cases, compared with $35.2 \%$ of the controls $(P<0.001)$. The OR were 0.23 (95\% CI: 0.1-0.38) for KIDMED index 4-7 and 0.06 (95\%
CI, 0.03-0.11) for KIDMED index $\geq 8$ compared with the lowest category (KIDMED index $\leq 3 ; P<0.001$ ).

There were statistically significant differences between cases and controls in their responses to selected KIDMED questions (Table 2). For example, daily consumption of fruits and vegetables was significantly lower in cases compared with controls $(40.3 \%$ versus $60.0 \%$, and $12.2 \%$ versus $32.6 \%$, respectively; $P<0.001$ ), while consumption of sweets several times a day was significantly higher in cases than controls $(68.7 \%$ versus $52.1 \%$ respectively; $P<0.001$ ). However, in a conditional logistic regression analysis, only consumption of vegetables regularly was significantly associated with functional constipation ( $\mathrm{OR}=0.44 ; 95 \% \mathrm{CI}$ : 0.24-0.81).

Analysis by age groups showed that high-school students had lower KIDMED index scores than elementary school students, although the difference was not statistically significant (Table 3). In a linear regression model with KIDMED score as the dependent variable, a negative correlation was found between age and adherence to a Mediterranean diet $(B=-0.128 ; P=$ 0.001).

The association between adherence to a Mediterranean diet and risk of functional constipation is shown in 


\begin{tabular}{|c|c|c|c|c|}
\hline \multirow{2}{*}{ Variable } & Cases $(n=221)$ & Controls $(n=230)$ & P-value ${ }^{b}$ & OR $(95 \% C I)^{\mathrm{a}}$ \\
\hline & No. (\%) & No. (\%) & & \\
\hline $\begin{array}{l}\text { Consumes fruit regularly (at least two portions a } \\
\text { day) }\end{array}$ & \multicolumn{4}{|c|}{$<0.001$} \\
\hline Yes & $89(40.3)$ & $138(60.0)$ & & \multirow[t]{2}{*}{$0.69(0.45-1.05)$} \\
\hline No (Ref) & $132(59.7)$ & $92(40.0)$ & & \\
\hline \multicolumn{2}{|l|}{$\begin{array}{l}\text { Consumes vegetables regularly (at least two } \\
\text { portions a day) }\end{array}$} & \multicolumn{3}{|c|}{$<0.001$} \\
\hline Yes & $27(12.2)$ & $75(32.6)$ & & \multirow[t]{2}{*}{$0.44(0.24-0.81)$} \\
\hline No (Ref) & $194(87.8)$ & $155(67.4)$ & & \\
\hline \multicolumn{2}{|l|}{$\begin{array}{l}\text { Consumes fish regularly (at least two-three } \\
\text { portions a week) }\end{array}$} & \multicolumn{3}{|c|}{$<0.001$} \\
\hline Yes & $28(12.7)$ & $63(27.4)$ & & \multirow[t]{2}{*}{$0.64(0.41-1.02)$} \\
\hline No (Ref) & $193(87.3)$ & $167(72.6)$ & & \\
\hline \multicolumn{2}{|l|}{ Consumes olive oil at home } & \multicolumn{3}{|c|}{$<0.001$} \\
\hline Yes & $158(71.5)$ & 209 (90.9) & & \multirow[t]{2}{*}{$0.78(0.53-1.10)$} \\
\hline No (Ref) & $63(28.5)$ & $21(9.1)$ & & \\
\hline \multicolumn{2}{|l|}{ Likes and consumes pulses (more than once a week) } & \multicolumn{3}{|c|}{0.010} \\
\hline Yes & $150(67.9)$ & $182(79.1)$ & & \multirow[t]{2}{*}{$0.86(0.64-1.21)$} \\
\hline No (Ref) & $71(32.1)$ & $48(20.9)$ & & \\
\hline \multicolumn{2}{|l|}{ Consumes sweets several times a day } & \multicolumn{3}{|c|}{$<0.001$} \\
\hline Yes (Ref) & $152(68.8)$ & $120(52.2)$ & & $1.35(0.96-1.91)$ \\
\hline No & $69(31.2)$ & $110(47.8)$ & & \\
\hline
\end{tabular}

OR= odds ratio; $C I=$ confidence interval; Ref $=$ reference category.

${ }^{a}$ Adjusted for age, sex, body mass index, maternal and paternal educational level and socioeconomic status of family.

${ }^{b} \mathrm{P}<0.05$ statistically significant.

Table 4. Higher adherence to a Mediterranean diet (as measured by increasing KIDMED scores) was associated with a lower risk of constipation: fully adjusted OR for constipation $=0.71(95 \%$ CI: $0.51-1.00)$ for moderate KIDMED score and 0.35 (95\% CI: 0.22-0.59) for a high KIDMED score compared with a low KIDMED score. The OR for an increase in 1 point in the KIDMED score was 0.84 (95\% CI: $0.78-0.91)$.

\section{Discussion}

In this study, we observed that the KIDMED index score was inversely associated with risk of functional constipation in children, independent of confounding variables. Thus, children with functional constipation have lower compliance with the Mediterranean diet. In addition, adherence to the Mediterranean diet decreased with age.

Previous studies have shown that lower consumption of vegetables and fruits causes functional constipation (17,18), both of which are components of the Mediterranean diet. One of the most important causes of chronic constipation in children is insufficient dietary fibre intake (17-19). Unrefined whole cereal products and pulses are an important component of the Mediterranean diet - the Mediterranean diet provides 30-50 g/day of fibre (20). Oxidative stress has been observed in patients with constipation, as in those with colorectal cancer and other chronic illnesses (21). Oxidative stress causes intestinal dysmotility which in turn can lead to oxidative stress in a vicious circle (22). Olives and olive oil,

\begin{tabular}{|c|c|c|c|}
\hline Variable & $\begin{array}{l}\text { Elementary school students } \\
\qquad(\mathrm{n}=\mathbf{2 8 8})\end{array}$ & $\begin{array}{l}\text { High-school students } \\
\qquad(n=163)\end{array}$ & $P$-value \\
\hline KIDMED index score, mean (SD) & $5.2(2.6)$ & $4.7(2.8)$ & 0.066 \\
\hline Diet adherence, no. (\%) & & & 0.179 \\
\hline $\operatorname{Low}(\leq 3)$ & $77(26.7)$ & $53(32.5)$ & \\
\hline Moderate (4-7) & $150(52.1)$ & $82(50.3)$ & \\
\hline $\operatorname{High}(\geq 8)$ & $61(21.2)$ & $28(17.2)$ & \\
\hline
\end{tabular}




\begin{tabular}{|c|c|c|}
\hline Adherence & OR $(95 \% \mathrm{CI})^{\mathrm{a}}$ & OR $(95 \% \mathrm{CI})^{\mathrm{b}}$ \\
\hline Low $(\leq 3)$ & Ref & Ref \\
\hline Moderate (4-7) & $0.74(0.54-1.05)$ & $0.71(0.51-1.00)$ \\
\hline High $(\geq 8)$ & $0.38(0.23-0.65)$ & $0.35(0.22-0.59)$ \\
\hline Continuous $\mathrm{OR}^{\mathrm{c}}$ & $0.86(0.81-0.86)$ & $0.84(0.78-0.91)$ \\
\hline \multicolumn{3}{|c|}{$\begin{array}{l}\text { OR= odds ratio; CI = confidence interval; Ref= reference category. } \\
{ }^{a} \text { Adjusted for age and sex. } \\
{ }^{b} \text { Adjusted for age, sex, body mass index, maternal and paternal educational level and } \\
\text { socioeconomic status of family. } \\
\text { 'For an increase of } 1 \text { point in the KIDMED score. }\end{array}$} \\
\hline
\end{tabular}

important components of the Mediterranean diet exhibit antioxidant, antimicrobial and anti-inflammatory effects (23). A decrease in bifidobacteria and lactobacilli levels and an increase in Bacteroidetes spp. have been reported in adults with constipation compared with those without constipation (24-27). Although this finding has not been confirmed in children with constipation, intestinal flora disturbances such as increased Clostridium spp. and Enterobacteriaceae that are rarely seen in healthy children have been reported in children with functional constipation (28). Positive effects on intestinal microbiota have been reported in parallel with adherence to a Mediterranean diet in some studies (29-31). For instance, closer adherence to a Mediterranean diet has been shown to be associated with higher faecal short-chain fatty acids and lower levels of Firmicutes and Bacteroidetes species (31). However, the evidence for a positive effect of the Mediterranean diet on the microbiome is still insufficient (32).

A previous case-control study in adult reported lower adherence to a Mediterranean diet in patients with functional gastrointestinal system disease compared with a healthy control group (33). Another study in adults showed that low adherence triggered functional gastrointestinal symptoms (34). That study observed a lower adherence to the Mediterranean diet in people with functional gastrointestinal symptoms in younger age groups (17-24 years and 24-34 years) compared with older age groups. In a paediatric cohort study, less functional gastrointestinal disease was reported in children with good adherence to a Mediterranean diet (11). Functional constipation represented a significant proportion of the functional gastrointestinal diseases in that study (66\%) and KIDMED scores were significantly lower compared with the control group. However, KIDMED scores did not differ significantly between the group with functional constipation and groups with other functional gastrointestinal diseases. As a result, lack of adherence to a Mediterranean diet was identified as an independent predictor in the development of functional constipation. In our study, adherence to a Mediterranean diet was significantly lower in children with functional constipation than in healthy children.

In our study, $35.2 \%$ of the healthy children had good compliance with the Mediterranean diet, while $10.9 \%$ showed poor compliance, while most $(53.9 \%)$ had a moderate compliance. A study in Turkey with healthy adolescents aged 10-14 years reported that $17.9 \%$ of the participants had a poor compliance with the Mediterranean diet, 59.2\% moderate compliance and $22.9 \%$ good compliance (35). In our study, the proportion of children with good adherence to the Mediterranean diet was higher than previously reported. This difference between the results of the two studies may be due to the difference in age groups. Indeed, in our study, adherence to the Mediterranean diet was better in the elementary school students than in the high-school students. Adolescence is a period of transition from childhood to adulthood in which physical and psychological changes occur, involving various health problems caused by environmental stressors, risky behaviour and psychosocial needs. The tendency to eat outside the home increases during adolescence and changes in eating habits, including skipping main meals and fast-food snacking between meals, also develop. Sitting for extended periods and snacking while watching the television and using the computer is widely observed in adolescents. Children in this age group are therefore irregularly nourished, consume far less than the recommended portions of fruit and vegetables and consume high levels of saturated fat and sodium (36-38).

Our study has some limitations. The first is the relatively small sample size. Furthermore, the sample represented Turkish families with a moderate income. The results therefore cannot be generalized to other populations. Second, we did not evaluate the physical activities of the children taking part in the study.

In conclusion, we found a decrease in the development of functional constipation in children as adherence to the Mediterranean diet increased. The Mediterranean diet is an inexpensive regimen with protective health benefits. It can also be a therapeutic option in children with functional constipation, particularly in regions where its components of the Mediterranean diet are widely produced and consumed. Adherence to the Mediterranean diet among children in our study also decreased with age. With its psychological, physiological and social characteristics, adolescence is an important time of transition between childhood and adulthood that results in changes in feeding habits. The provision of education on nutrition and health in schools and particularly in the family is warranted to help maintain and improve the health of young people in Turkey.

Funding: None.

Competing interests: None declared. 


\section{Observance du régime méditerranéen et risque de constipation fonctionnelle chez les enfants en Turquie : étude cas-témoins}

\section{Résumé}

Contexte: Une constipation fonctionnelle est souvent observée chez les enfants, ce qui affecte la qualité de vie et impose une charge considérable aux services de soins de santé. Le régime méditerranéen est associé à un risque plus faible de troubles gastro-intestinaux fonctionnels.

Objectifs : La présente étude visait à évaluer la relation entre la constipation fonctionnelle et l'observance du régime méditerranéen chez des enfants turcs âgés de 6 à 18 ans.

Méthodes: Dans cette étude cas-témoins, 221 enfants souffrant de constipation fonctionnelle (cas) ont été sélectionnés dans une clinique de gastro-entérologie pédiatrique entre mai 2018 et septembre 2019. En outre, 230 enfants sans constipation (témoins) ont été sélectionnés aléatoirement parmi ceux qui effectuaient une visite de contrôle. Les cas et les témoins étaient appariés sur la base du sexe, de l'âge et des caractéristiques socioéconomiques. L'observance du régime méditerranéen a été évaluée à l'aide du score KIDMED. Une analyse de régression logistique multivariée a été utilisée pour analyser les données.

Résultats: Les scores KIDMED chez les cas et les témoins étaient de 4,0 (écart type (ET) 2,5) et 6,3 (ET 2,4), respectivement $(p<0,001)$. Les odds ratios pour la constipation fonctionnelle étaient de 0,23 (intervalle de confiance (IC) à $95 \%$ : 0,13-0,38) pour le score KIDMED 4-7 et de 0,05 (IC à $95 \%$ : 0,03-0,11) pour le score supérieur ou égal à 8 par rapport à la catégorie la plus faible (score $\leq 3 ; p<0,001$ ). Une corrélation négative a été observée entre l'âge et l'observance du régime méditerranéen.

Conclusion: Une bonne observance du régime méditerranéen était associée à un risque plus faible de constipation fonctionnelle, et cette observance diminuait avec l'âge. L'éducation nutritionnelle et sanitaire est nécessaire pour aider à maintenir et à améliorer la santé des jeunes en Turquie.

$$
\begin{aligned}
& \text { الالنزام بالنظام الغذائي المتوسطي، وخطر الإصابة بالإمساك الوظيفي لدى الأطفال في تركيا: دراسة حالات إفرادية }
\end{aligned}
$$

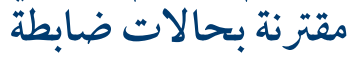

$$
\begin{aligned}
& \text { أولاسي أقبلت، إسحق إيزاك، عتيقة أتلاي، إسماعيل توبال }
\end{aligned}
$$

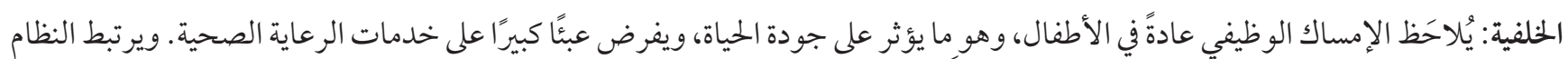

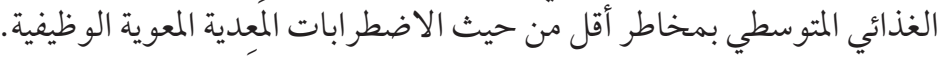
الأهداف: هدفت هذه الدراسة المى تقييم العلاقة بين الإمساك الوظيفي والالتزام بالنظام الغذائي المتوسطي بين الأطفال الأتراك الذين تتراوح

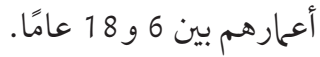

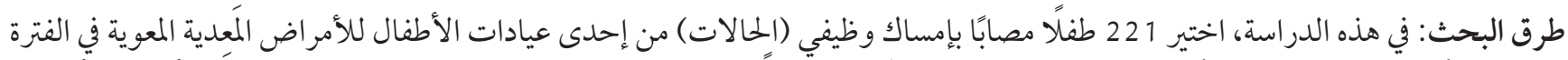

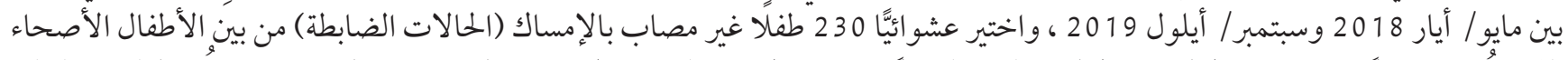

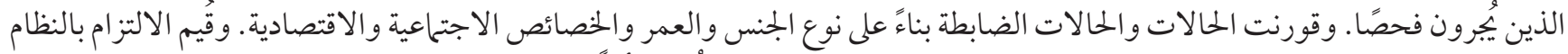

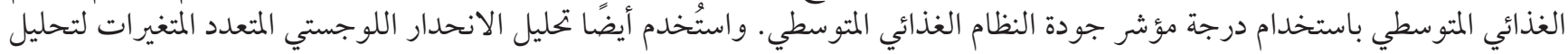
البيانات.

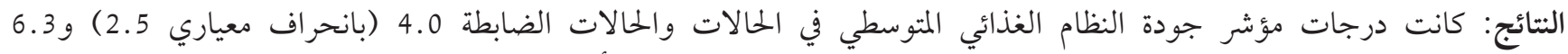

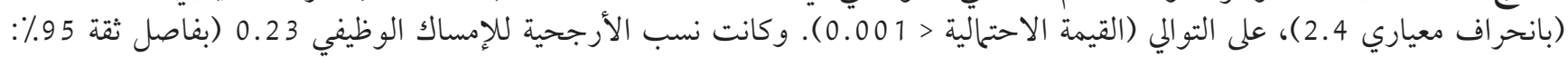

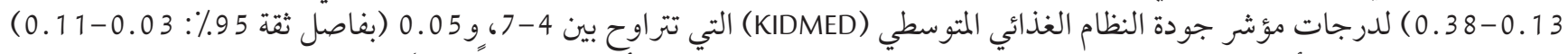

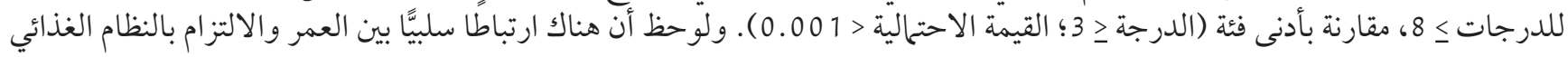
المتوسطي.

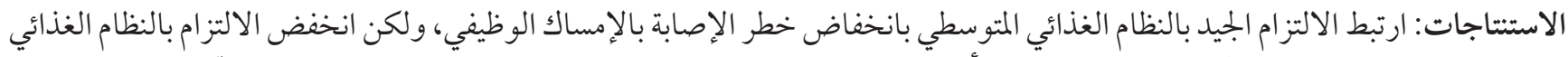

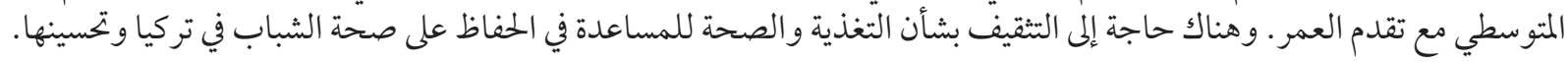




\section{References}

1. Koppen IJ, Vriesman MH, Saps M, Rajindrajith S, Shi X, van Etten-Jamaludin FS, et al. Prevalence of functional defecation disorders in children: a systematic review and meta-analysis. J Pediatr. 2018;198:121-30e6. https://doi.org/10.1016/j.jpeds.2018.02.029.y

2. Park R, Mikami S, LeClair J, Bollom A, Lembo C, Sethi S, et al. Inpatient burden of childhood functional GI disorders in the USA: an analysis of national trends in the USA from 1997 to 2009. Neurogastroenterol Motil. 2015;27(5):684-92. https://doi.org/10.1111/ nmo.12542

3. Dehghani SM, Kulouee N, Honar N, Imanieh MH, Haghighat M, Javaherizadeh H. Clinical manifestations among children with chronic functional constipation. Middle East J Dig Dis. 2015;7(1):31-5.

4. Hyams JS, Di Lorenzo C, Saps M, Shulman RJ, Staiano A, van Tilburg M. Functional disorders: children and adolescents. Gastroenterology. 2016;150(6):1456-68. https://doi.org/10.1053/j.gastro.2016.02.015

5. Mugie SM, Di Lorenzo C, Benninga MA. Constipation in childhood. Nat Rev Gastroenterol Hepatol. 2011;8(9):502-11. https://doi. org/10.1038/nrgastro.2011.130

6. Morais MB, Vitolo MR, Aguirre AN, Fagundes-Neto U. Measurement of low dietary fiber intake as a risk factor for chronic constipation in children. J Pediatr Gastroenterol Nutr. 1999;29(2):132-5. https://doi.org/10.1097/00005176-199908000-00007

7. Butte NF, Fox MK, Briefel RR, Siege-Riz AM, Dwyer JT, Deming DM, et al. Nutrient intakes of US infants, toddlers, and preschoolers meet or exceed dietary reference intakes. J Am Diet Assoc. 2010;110(Suppl. 12):S27-37. https://doi.org/10.1016/j. jada.2010.09.004

8. Bach-Faig A, Berry EM, Lairon D,Reguant J, Trichopoulou A, Dernini S. et al. Mediterranean diet pyramid today. Science and cultural updates. Public Health Nutr. 2011;14(12A):2274-84. https://doi.org/10.1017/S1368980011002515

9. Cakir M, Akbulut UE, Okten A. Association between adherence to the Mediterranean diet and presence of nonalcoholic fatty liver disease in children. Child Obes. 2016;12(4):279-85. https://doi.org/10.1089/chi.2015.0197

10. Ramezan M, Asghari G, Mirmiran P, Tahmasebinejad Z, Azizi F. Mediterranean dietary patterns and risk of type 2 diabetes in the Islamic Republic of Iran. East Mediterr Health J. 2019;25(12):896-904. https://doi.org/10.26719/emhj.19.035

11. Agakidis C, Kotzakioulafi E, Petridis D, Apostolidou K, Karagiozoglou-Lampoudi T. Mediterranean diet adherence is associated with lower prevalence of functional gastrointestinal disorders in children and adolescents. Nutrients. 2019;11(6):pii E1283. https:// doi.org/10.3390/nu11061283

12. Ergin A, Hatipoglu C, Bozkurt AI, Mirza E, Konak D, Karan C, et al. [Knowledge and attitudes of residents and medical students on complementary-alternative medicine.] Pamukkale Med J. 2011;4(3):136-43. [Turkish].

13. Currie CE, Elton RA, Todd J, Platt S. Indicators of socioeconomic status for adolescents: the WHO health behaviour in schoolaged children survey. Health Educ Res. 1997;12(3):385-97. https://doi.org/10.1093/her/12.3.385

14. Cole TJ, Bellizzi MC, Flegal KM, Dietz WH. Establishing a standard definition for child overweight and obesity worldwide: international survey. BMJ. 2000;320(7244):1240-3. https://doi.org/10.1136/bmj.320.7244.1240

15. Serra-Majem L, Ribas L, García A, Pérez-Rodrigo C, Aranceta J. Nutrient adequacy and Mediterranean diet in Spanish school children and adolescents. Eur J Clin Nutr. 2003;57(Suppl. 1):S35-9. https://doi.org/10.1038/sj.ejcn.1601812

16. Kabaran S, Gezer C. [Determination of the Mediterranean diet and the obesity status of children and adolescents in Turkish Republic of Northern Cyprus.] Turkish J Ped Dis. 2013;7(1):11-20. https://doi.org/10.12956/tjpd.2013.1.03 [Turkish]

17. Okuda M, Kunitsugi I, Yoshitake N, Sasaki S. The relationship between functional constipation and dietary habits in school-age Japanese children. J Nutr Sci Vitaminol (Tokyo). 2019;65(1):38-44. https://doi.org/10.3177/jnsv.65.38

18. Asakura K, Masayasu S, Sasaki S. Dietary intake, physical activity, and time management are associated with constipation in preschool children in Japan. Asia Pac J Clin Nutr. 2017;26(1):118-29. https://doi.org/10.6133/apjcn.112015.02

19. Fujitani A, Sogo T, Inui A, Kawakubo K. Prevalence of functional constipation and relationship with dietary habits in 3- to 8-yearold children in Japan. Gastroenterol Res Pract. 2018:27;3108021. https://doi.org/10.1155/2018/3108021

20. Chauveau P, Aparicio M, Bellizzi V, Campbell K, Hong X, Johansson L, et al. European Renal Nutrition (ERN) Working Group of the European Renal Association-European Dialysis Transplant Association (ERA-EDTA). Mediterranean diet as the diet of choice for patients with chronic kidney disease. Nephrol Dial Transplant. 2018;33(5):725-35. https://doi.org/10.1093/ndt/gfxo85

21. Vermorken A, Andres E, Cui Y. Chronic constipation - a warning sign for oxidative stress? Aliment Pharmacol Ther. 2015;42(3):385-6. https://doi.org/10.1111/apt.13257

22. Kashyap P, Farrugia G. Oxidative stress: key player in gastrointestinal complications of diabetes. Neurogastroenterol Motil. 2011;23(2):111-4. https://doi.org/10.1111/j.1365-2982.2010.01659.x

23. Omar SH. Oleuropein in olive and its pharmacological effects. Sci Pharm. 2010;78(2):133-54. https://doi.org/10.3797/scipharm.0912-18

24. Khalif IL, Quigley EM, Konovitch EA, Maximova ID. Alterations in the colonic flora and intestinal permeability and evidence of immune activation in chronic constipation. Dig Liver Dis. 2005;37(11):838-49. https://doi.org/10.1016/j.dld.2005.06.008

25. Chassard C, Dapoigny M, Scott KP, Crouzet L, Del'homme C, Marque P, et al. Functional dysbiosis within the gut microbiota of patients with constipated-irritable bowel syndrome. Aliment Pharmacol Ther. 2012;35(7):828-38. https://doi.org/10.1111/j.13652036.2012.05007.X 
26. Kim SE, Choi SC, Park KS, Park MI, Shin JE, Lee TH, et al. Change of fecal flora and effectiveness of the short-term VSL\#3 probiotic treatment in patients with functional constipation. J Neurogastroenterol Motil. 2015;21(1):111-20. https://doi.org/10.5056/ jnm14048

27. Parthasarathy G, Chen J, Chen X, Chia N, O'Conner HM, Wolf PG, et al. Relationship between microbiota of the colonic mucosa vs feces and symptoms, colonic transit, and methane production in female patients with chronic constipation. Gastroenterology. 2016;150(2):367-79. https://doi.org/10.1053/j.gastro.2015.10.005.

28. Zoppi G, Cinquetti M, Luciano A, Benini A, Muner A, Bertazzoni Minelli E. The intestinal ecosystem in chronic functional constipation. Acta Paediatr. 1998;87(8):836-41. https://doi.org/10.1080/080352598750013590

29. De Filippis F, Pellegrini N, Vannini L, Jeffery IB, Storia AL, Laghi L, et al. High-level adherence to a Mediterranean diet beneficially impacts the gut microbiota and associated metabolome. Gut. 2016;65(11):1812-21. https://doi.org/10.1136/gutjnl-2015-309957

30. Pastori D, Carnevale R, Nocella C, Novo M, Santulli M, Cammisotto V, et al. Gut-derived serum lipopolysaccharide is associated with enhanced risk of major adverse cardiovascular events in atrial fibrillation: effect of adherence to Mediterranean diet. J Am Heart Assoc. 2017;6(6):e005784. https://doi.org/10.1161/JAHA.117.005784

31. Garcia-Mantrana I, Selma-Royo M, Alcantara C, Collado MC. Shifts on gut microbiota associated to Mediterranean diet adherence and specific dietary intakes on general adult population. Front Microbiol. 2018;9:890. https://doi.org/10.3389/ fmicb.2018.00890

32. Jin Q, Black, A, Kales SN, Vattem D, Ruiz-Canela M, Sotos-Prieto M. Metabolomics and microbiomes as potential tools to evaluate the effects of the Mediterranean diet. Nutrients. 2019;11(1):207. https://doi.org/10.3390/nu11010207

33. Elmaliklis IN, Liveri A, Ntelis B, Paraskeva K, Goulis I, Koutelidakis AE. Increased functional foods' consumption and Mediterranean diet adherence may have a protective effect in the appearance of gastrointestinal diseases: a case-control study. Medicines. 2019;6(2):50. https://doi.org/10.3390/medicines6020050

34. Zito FP, Polese B, Vozzella L, Gala A, Genovese D, Verlezza V, et al. Good adherence to Mediterranean diet can prevent gastrointestinal symptoms: a survey from southern Italy. World J. Gastrointest Pharm. 2016;7(4):564-71. https://doi.org/10.4292/wjgpt. v7.i4.564

35. Sahingoz SA, Sanlier N. Compliance with Mediterranean diet quality index (KIDMED) and nutrition knowledge levels in adolescents. A case study from Turkey. Appetite. 2011;57(1):272-7. https://doi.org/10.1016/j.appet.2011.05.307

36. Garipağaoğlu M, Sahip Y, Budak N, Akdikmen O, Altan T, Baban Ml. Food types in the diet and the nutrient intake of obese and non-obese children. J Clin Res Pediatr Endocrinol. 2008;1(1):21-9. https://doi.org/10.4008/jcrpe.vii1.5

37. Vadiveloo M, Zhu L, Quatromoni PA. Diet and physical activity patterns of school-aged children. J Am Diet Assoc. 2009;109(1):145-51. https://doi.org/10.1016/j.jada.2008.10.012

38. Arcan C, Neumark-Sztainer D, Hannan P, van den Berg P, Story M, Larson N. Parental eating behaviours, home food environment and adolescent intakes of fruits, vegetables and dairy foods: longitudinal findings from Project EAT. Public Health Nutr. 2007;10(11);1257-65. https://doi.org/10.1017/S1368980007687151 